\title{
Infrequency Scale
}

National Cancer Institute

\section{Source}

National Cancer Institute. Infrequency Scale. NCI Thesaurus. Code C159492.

Measures the extent to which the respondent endorsed items in an atypical fashion. This consists of three items where marking Sometimes or Often to any of the items is highly unusual, even for adolescents with severe cognitive impairment. 